\title{
O DESENHO ANIMADO E O ENCANTO DO HERÓI DA TV
}

Alexandre Silva dos SANTOS FILHO ${ }^{1}$

Universidade Federal do Pará

alixandresantos@gmail.com

Resumo: Brincar com desenhos animados é bastante revelador. Eles permitem a criança ter um papel no processo de relacionamento e interação, afetando, portando, o significado lúdico. O objetivo é refletir sobre o papel da representação gráfica da criança como fator mediador no comportamento lúdico. Desse modo, o presente trabalho também discute o significado do brinquedo gráfico na vida das crianças, especialmente, quando influenciadas pelo personagem do herói de desenhos animados. Para tanto, tenta-se trazer importantes conceitos, tais como: liminal e liminoid, que caracterizam o comportamento lúdico da criança, entre a arte e o brincar; a ludicidade como natureza consequencial; o entretenimento - sensivel e livre; e os mecanismos da imaginação. Esta reflexão toma como referências imagéticas os desenhos animados exibidos na TV brasileira. Dir-se-á, por fim, que o brincar com os personagens de heróis na forma gráfica promove o relacionamento e a capacidade de interação com outras crianças.

Palavras chave: Entretenimento. Imaginação. Liminal. Liminoid. Ludicidade.

Abstract: Playing with animated cartoons is quite revealing. They allow the child to play a role in the relationship and interaction process, affecting thus the ludic meaning. The aim is to reflect on the role of the child's graphic representation as the mediating factor in ludic behaviour. Therefore, this paper also discusses the meaning of the graphic toy in the lives of children, especially when influenced by hero characters from animated cartoons. It also attempts to bring important concepts together, such as: liminal and liminoid, which characterise the ludic behaviour between art and child's play; ludicity as an element of consequential nature; entertainment - sensitive and free; and imagination mechanisms. This reflection is based on the image references of animated cartoon series broadcast on Brazilian television. Finally, it will be said that playing with graphic forms of hero characters promotes relationship capacity and interaction with other children.

Keywords: Entertainment. Imagination. Liminal. Liminoid. Ludicity.

\footnotetext{
${ }^{1}$ Mestre em Comunicação e Cultura Contemporânea, doutorando em Educação, na Universidade Federal de Goiás. Atualmente realiza estágio de doutoramento na Universidade de Aveiro, Portugal.
} 


\section{Elementos introdutórios}

Desde a década 1950, no Brasil, a televisão tem sido um dos aportes midiáticos mais importantes na cultura de massa nacional. A cultura da criança tem se imiscuído nessa construção simbólica e em muitos aspectos a televisão tem se apropriado de uma pedagogia para se aproximar da infância. Sob este ponto de vista, é considerável repensar o efeito dos desenhos animados na vida das crianças, como evento central e participante do brincar. Destacar-se-á, nessa confluência, o papel da representação gráfica, no processo da imaginação da criança, dos heróis que se apresentam por meio dos desenhos animados pela TV.

Este texto é uma construção teórica, desenvolvendo-se sob dois aspectos de interface entre a cultura estética e a cultura lúdica. Como método meditativo, busca-se enlaçar a dimensão estética vinculada à produção material e social humana, cuja observação consiste em estabelecer o brinquedo conectado à forma sensível da imaginação da criança no seu ato criador. Afasta-se, então, a possibilidade do adulto realizar qualquer interferência no seu brincar livre e espontâneo, posto que o brinquedo para a criança será aquele que aparece quando o adulto se separa inteiramente dela (BENJAMIN, 1984).

Nessa perspectiva, encontra-se o significado da criança - sob o efeito do herói no desenho animado da TV - ela cria a sua representação gráfica, o seu próprio brinquedo, cuja denominação será designada por desenho-brinquedo. A razão de tal qualificação rege-se pelo fato de que essa atividade intelectual da criança está impregnada pela manifestação de ludicidade. Torna-se necessário, então, entender a essência da ludicidade como processo relacional e de interação, já que implica em significação lúdica dos comportamentos dos infantes. Chama-se também a atenção para a questão de que o mecanismo examinado nessa reflexão é do âmbito comunicacional e que engendra o aspecto educacional, por isso ser de natureza consequencial, à qual a ludicidade participa em toda a extensão da vida do homem. Dada esta ênfase, pressupõe-se que o brinquedo seja um artefato lúdico que a criança aplica a criatividade para se comunicar. Destaca-se, ainda, que a relação entre a arte da criança e a brincadeira caracterizam-se por dois conceitos denominados de liminal e liminoid. 
O segundo momento dessa discussão suporta o sentido promovido pela comunicação do desenho gráfico da criança e que se torna entretenimento livre ou físico, uma vez que, o desenho-brinquedo participa de uma ação espontânea da criança, porém no contato com a TV esta solicita intensamente o corpo físico do infante. Tal afecção é dada pelas sensações agradáveis, cujos efeitos sensoriais produzem apenas prazeres imediatos e superficiais, mas não caracterizam um modo de articular o sentimento de prazer estético e por isso não alcançam a manifestação de ludicidade livre. Pois, seria preciso a ressignificação do comportamento lúdico. Considera-se que o papel da ressignificação lúdica, no âmbito da ação gráfica da criança seja um meio de requerer para si a expressão, a liberdade, o saber e a memória. Desse modo, o desenho animado pode interferir como um importante mediador da imaginação da criança.

No terceiro momento desta reflexão, descrever-se-á o processo de elaboração do brinquedo e da atividade de desenhar espontaneamente da criança a partir da observação das imagens que passam no écran da televisão. Tomando como modelo o herói na TV a criança se desafia. Perceber-se-á que existe um enorme esforço de aprendizado: ampliando a imaginação; desenvolvendo habilidades; praticando o desenho de observação; e armazenando repertórios visuais. Procura-se compreender quais os mecanismos da imaginação lúdica sob os impulsos: da criação ou plástica, da associação e da afinidade ou estética. Esclarecer-se-á que a experiência receptiva não pode se subordinar ao entretenimento físico e impossibilitar a liberdade, já que duas situações estão postas: não confundir o faz-de-conta com reprodução e nem sensibilização com comunicabilidade.

\section{A ludicidade no processo de relação e interação, o liminal e o liminoid}

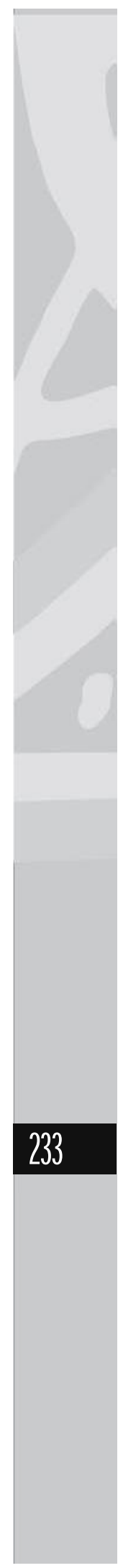

Quando se fala em brinquedo, logo vem à mente a ideia de uma forma caracteristicamente dada por um artefato capaz de promover um efeito no brincar. Porém, deve-se observar um outro fator, que nem sempre emerge da sua ideação, mas que consiste em considerá-lo com sendo um suporte que conduz uma mensagem e contém ludicidade. 
Pois, é imprescindível lembrar que o brinquedo é um artefato lúdico e que evidencia criatividade (LOPES, 2008).

Nesse sentido, Lopes (2008) caracteriza-o com a essência da ludicidade, cujo propósito se estabelece por meio de um processo relacional e interacional, ou seja, implica em considerar que o comportamento humano se reveste em uma significação e que este só pode ser de conotação lúdica. Afinal, este processo, ao se forrar de tal significação, traduzir-seá, então, em comunicação. Logo, a ludicidade será vislumbrada como comunicação, porque se dá pelo pacto entre as pessoas que implica em significação lúdica dos seus comportamentos (Ibid.).

Acomunicabilidade lúdica revelar-se-á por meio de uma diversidade de comportamentos e objetos existentes, visto que a ludicidade emerge do próprio ser e é nomeada de diferentes maneiras, tais como: brincar, jogar, recrear, lazer e construir artefatos lúdicos e de criatividade (LOPES, 2008). O princípio apresenta-se claro nas palavras de Lopes: "ao emergir da essência do próprio ser, a ludicidade é o próprio ser” (2008, p. 3). Ora, se o que constitui a natureza do processo relacional e interacional está aventado por uma significação lúdica, então, se traduz em um fenômeno de natureza consequencial à espécie humana.

A referência ao conceito de consequencialidade serve aqui para atribuir uma qualidade e um estado (CRONEN, 1995). Explica-se que, se na condição de homo ludens o ser humano se integra em diversas manifestações, é porque há de se considerar os efeitos sobre ele mesmo. Nessa perspectiva, a natureza consequencial prima em afirmar que a ludicidade não é somente requisito de uma fase do homem, mas pertence a toda a extensão da vida humana, independentemente de faixa etária, opera em três dimensões indissociáveis, conforme Lopes (2008): 1) Dimensão da condição humana; 2) Dimensão da manifestação; 3) Dimensão dos efeitos.

Lopes (2008) esclarece que a dimensão da condição humana é dada unicamente pelo ser humano, só a ele é possível atribuir tal desígnio, já que sua existência prepara a esfera cultural e comunicacional. O estado lúdico aparece na Dimensão da manifestação, pois é decorrente de diversas percepções que se inscrevem sob as modalidades do brincar, jogar, recrear, lazer e construir artefatos e criatividade. Na dimensão dos efeitos, a diversidade é fruto da interatividade, cujos efeitos se revelam somente 
nos resultados de tais processos. Nesse sentido, a consequencialidade enuncia: "a ludicidade é o lugar da ação onde a intencionalidade lúdica é criada por cada indivíduo que assim se exprime” (LOPES, 2008, p. 3). Tal modo de representar a manifestação da ludicidade é inexorável à condição humana, pois é a própria vida dos homens e mulheres, crianças e adultos em questão.

Tudo quanto foi dito, deve-se notar na constituição da manifestação da ludicidade sobre a cultura da criança, já que o princípio é não separála a criança como sendo um ser indiferente da cultura humana. Pois, desde que se propôs que se olhasse para ela como não sendo homem e mulher em tamanho reduzido é que se inaugurou uma fase a mais na formação humana - adulto e criança. Por outro lado, afastou da criança a ideia de ser humana, já que não pertenceria mais ao mundo adulto: a relutância "inclusive [era] em aceitá-la como pequenos seres humanos" (BENJAMIN, 2002, p. 86). Por esta falta é que se rejeitaria a criança constituída na ideia de consequencialidade. Mas, pelo contrário, a essência da ludicidade reside no processo da condição humana e toma para si a criança igual a qualquer outro ser humano, a única diferença consiste na protagonização dela, cuja atribuição do seu comportamento há que consistir em uma significação lúdica.

A significação lúdica pretendida admite dois movimentos distintos que podem ser destacados para caracterizar a ordem da ação. Chamase então os conceitos identificados por Wilson e Wilson (1997), para suportar uma pertinência junto ao comportamento lúdico, os quais se definem com uma estreita relação entre arte da criança e a brincadeira: um designar-se-á por liminal e o outro chamar-se-á liminoid. No que concerne ao aspecto condicionante liminal, dir-se-á que é um fator limitante, restritivo e orientado por regras. Porém, o liminoid atua ultrapassando qualquer limite estabelecido por regras, estimulante, impulsivo e redutor de tensão. E, por isso, admite-se que "a arte espontânea [das crianças] é brincadeira por excelência concorrência", o que se enquadra no campo da manifestação da ludicidade livre (WILSON; WILSON, 1997, p. 6).

Wilson \& Wilson (Ibid.) observaram que quando as crianças estão no dever de realizar arte na escola, elas o fazem pela obrigação. Porém, há um sentido da manifestação lúdica que se formata na aula de arte, já que as atividades são orientadas por regras e se caracterizam por um momento 
liminal. Contrariando essa posição da arte na educação, está disponível na sociedade de produção e consumo todo um aparato que serve para impregnar a criança com uma padronização dos valores instituídos pela cultura de massa, vinculados à mídia televisual. Isso tem induzido o comportamento dos espectadores mirins na contemporaneidade que se estabelecem diante da TV envolvidos pela programação infantil, devido a afinidade com a linguagem visual.

Essa concepção tem influído bastante no modo de vida das crianças brasileiras, que se relacionam com os meios de comunicação como se fosse algo natural. Fusari (2002) assinala a seguinte questão: as crianças

[...] recebem influências de diversas qualidades e níveis para viverem no mundo contemporâneo [...] produzem suas influências infantis ao elaborar, recriar, expressar suas emoçoes, idéias, histórias junto a seus familiares, colegas, professores, com significados encontrados em programas assistidos pela TV (FUSARI, 2002, p.145).

Sobre esse aspecto, dir-se-á que a programação televisual tem dado conta de instituir valores de diversas ordens. Mas a façanha, que melhor caracteriza essa conjuntura, pode ser identificada pela consequencialidade da dimensão do efeito processual que a mídia exerce sobre o espectador mirim, por ser este apanhado pelo aspecto do entreter-se. Isso pode facilmente ser observado no cotidiano, já que a televisão toma conta das crianças na maior parte do tempo, diariamente.

De certa forma, a criança se depara diante de duas conformações, que pretendem possibilitá-la a atuar ludicamente, e tenderá a se defrontar: uma pela obrigatoriedade de fazer arte na escola; e a outra pela influência midiática dos programas televisuais. Em qualquer das situações perceber-se-á que a criança está subordinada ao modelo de ver o mundo sob a concepção do adulto. No entanto, há de se convir que a preparação da sociedade sob o feitio de uma racionalidade conduzida pelos adultos pretende garantir a continuidade cultural para as próximas gerações humanas, tipicamente, organizadas em comunidades urbanas administradas (ARENDT, 2007).

A ideia, que conduz a TV aos domicílios, às crianças, está calcada no ideacional do entretenimento, por essa razão é respeitável repensar as influências que os desenhos animados exercem na vida das crianças, 
sejam eles dados aos infantes através do écran da televisão (a cabo ou comercial) ou pelo sinal de DVD. Assistir ao desenho animado não é, simplesmente, estabelecer contato com a imagem em movimento, mantendo-se como espectador, cuja parcialidade consiste em olhar. Observa-se que nessa condição a manifestação processual da atividade lúdica se condicionada a uma forma programada de entretenimento e que não exige o compartilhamento da atividade com outra criança, basta a interação sensorialmente com a imagem em movimento. A interação sensorial com a imagem animada é uma tentativa de a criança se divertir de algum modo, já que o contato estabelecido, nessa modalidade, é constituído pelo aparato eletrônico que serve de meio para vincular uma forma de instituir o mundo adulto à criança.

Propositadamente, a influência da modelação do pensamento da criança interfere na forma de sua representação gráfica. É interessante notar que essa abordagem sutil da imagem técnica da animação revela um jeito de se relacionar com a criança sem obrigá-la a aceitar seus efeitos. A interatividade sensorial protagoniza a exigência de uma significação lúdica, nesse ato: o prazer no agradável publiciza a ideia de diversão; e a mentalidade aminista da criança ilude o sentido da realidade, tornando mais real devido as técnicas de animação. Este tipo de exponibilidade técnica é capaz de possibilitar a descarga de tensões estimulada pela "história" dos heróis prediletos da criança, tal motivação poderia ser caracterizada como liminoid, se a televisão não fosse uma instituição preocupada com o índice de audiência, ou seja, seu interesse subjacente é apenas com o lucro.

Sob este ponto de vista, o aspecto liminoid que cerca a criança subsume-se ao modelo hegemônico instituído pela televisão, pois exige interatividade sensorial e parcialidade para assistir à programação. Entrementes, a dimensão dos efeitos processuais não institui esse caráter, uma vez que, o seu destaque zela pela ludicidade comunicacional e não pelo uso desta para modelar comportamentos. Para a criança tudo que se relaciona de forma liminal deve ser "chatice" e o que toma a feição de liminoid é "interessante". Poder-se-ia pensar se é possível estabelecer equilíbrio entre uma atividade considerada, pelas crianças, como "chata" e outra "interessante".

Se as aulas de artes regradas são maçantes para as crianças, como podem expressar-se livremente? Haveria oportunidade de se organizar aula de arte na qual elas poderiam brincar com as imagens? Sem dúvida 
que aproximar a imagem animada da criança poderia produzir um efeito enriquecedor na qualidade e no envolvimento dela com a efetiva ludicidade. Aliás, se a dimensão da manifestação lúdica, em diferentes situações, pode oferecer comunicabilidade estética às crianças, então, é possível que os elementos plásticos e visuais, técnicos e eletrônicos, quotidianamente, possibilitem o contato da criança com os suportes sintagmáticos dessa linguagem e se tornem algo significativo em sua expressividade gráfica e corporal. Deve-se compreender que a criança que passa horas diante da TV está sendo alfabetizada para e com a linguagem televisual, isso proporciona a aquisição de elementos não-verbal e um modo de mediatizar o seu brincar, consequentemente, tornar-se-á uma forma de pensar o mundo sob os aparatos dessa linguagem.

Todavia, se o desenho animado estabelece-se sobre a criança, seduzindo-a, contrariando a chatice, não se impondo e nem instituindo regras visíveis, irá aparecer como sendo liminoid. Ora, se tais regras estão veladas e as que se vinculam ao conceito de diversão estão explícitas e aceitas pela intencionalidade que produz no estado lúdico, então, a própria criança se desvanece dos valores impostos quando se dispõe a abandonálos, em vista de que na condição lúdica permanece a intencionalidade do ato. Essa disposição só ocorre quando a imaginação criadora é mediadora da manifestação de ludicidade livre, ou seja, quando a criança desapropria o artefato animado do écran e pode livremente manipulá-lo a seu modo. Criando, assim, conexões com diversas experiências (não lúdicas), “[...] criticando-as, mudando-as, reformulando-as e abandonando-as, na situação criada a partir do pacto inicial estabelecido" (LOPES, 2008). Dependendo da relação que a criança tem com o desenho animado, será necessário haver uma intencionalidade voltada para o aspecto da criticidade, uma vez que, as mídias que se vinculam na sociedade fazem parte da dimensão dos efeitos e que é preciso, por fim, constituí-las como resultados da interação lúdica da própria criança.

No que tange a esta última, em face de a criança brincar com a imagem do desenho animado, tenderia a ancorar-se nela por sua predileção. Traduzida, então, pelo seu temperamento momentâneo, necessidade de satisfação imediata, superação de fadiga e chatice ou pelo "momento de solidão". A criança, que desenha, simplesmente conforme afirma Luquet (1969), precisa se divertir com algo mais. Porém, revela sua fragilidade 
afetiva quando se limita a passar horas diante do écran, sem um objetivo maior do que o puro entretenimento físico. Inevitavelmente, estará subsumida aos aspectos ideológicos e colonizadores apresentados pelas séries que passam no écran como, por exemplo, dos animes.

\section{$2 \mathrm{O}$ papel do entretenimento na ludicidade da criança}

É importante ressaltar que o desenvolvimento do esboço gráfico, que a criança vai apreendendo aos poucos, parte do exercício do desenho de observação espontaneamente. Esta condição só é consubstanciada pelo aspecto liminoid que caracteriza a atividade espontânea e cuja intencionalidade inaugura a esfera da ludicidade. Destaca-se, ainda, a forma como se dá a figuração dos heróis da TV, representados graficamente pela criança, os quais vão se transformando em brinquedo. Percebe-se, por outro lado, que a criança exerce um enorme esforço de aprendizado, já que está em jogo a imaginação, o desenvolvimento de habilidades, a constituição dos repertórios visuais e a experiência de cunho artístico e estética.

O entretenimento conseguido no ato liminoid de desenhar personagens do écran, não deve ser restritivo à sensação física no ato de entreter-se. Se assim ocorresse, acabaria com o que o ser humano tem de mais precioso, a criatividade. O entretenimento deve conter coeficientes apurados do estético para valer a pena ser um entreter-se que possibilite à criança vivenciar todos os aspectos de uma ação lúdica transformadora em sociedade.

Sobre este ponto de vista, Schiller (1991) chama atenção para o fato de ser o entretenimento o elemento ordinário capaz de produzir resultados meramente superficiais. Porém, contraditoriamente, é este mesmo entretenimento que sob a influência do estado lúdico transforma o afazer sério, cujo fim deve cumprir o seu efeito estético ao máximo, diz o autor: "[...] somente seria arte o que fosse objeto de um livre entretenimento, ou seja, o bom-gosto na disposição, que deleite o nosso entendimento, mas não os estímulos físicos em si, que só entretêm a nossa sensibilidade" (SCHILLER, 1991, p.16-17). Nessa perspectiva teórica, Schiller concebe o entretenimento de duas formas: o entretenimento livre e o sensível (físico). 
O entretenimento é livre quando "[...] se tornam ativas as faculdades espirituais, a razão e a imaginação, e sempre que o sentimento for gerado por uma representação" (SCHILLER, 1991, p. 16). Quer dizer que, prima pelo entreter-se no fazer criativo, pelo prazer estético de onde emana a substância lúdica, cuja proximidade se faz na dimensão da condição humana. Em oposição ao entretenimento livre, está o entretenimento sensível, peculiarmente estimulante, regido pelo prazer sensorial, um prazer fisiológico, contrariando a beleza, calcado em uma sensação de ser apenas agradável, impugnando a relação com o estado lúdico que só se alcança por meio do estético. A conclusão schilleriana é que não é a arte que se submete ao entretenimento sensível, é o entretenimento livre que se alcança através da arte, ou seja, a causa do entretenimento livre deve ser a estética.

Então, a partir do pressuposto schilleriano, poder-se-ia dizer que a criança, ao estabelecer relação com ambientes eletrônicos do écran, tem contato com uma comunidade de estímulos sensoriais, cuja finalidade precípua é capturar o infante por meio da sensorialidade premente. Sumarizando-se no entretenimento físico, a relação plástico-visual, que a criança tem com a imagem animada na TV, é simplesmente afetada pelas sensações agradáveis daquilo que está a vê. Não se pode dizer ao certo se a criança está a vivenciar algo, nesse momento, no écran. Mas se pode confirmar (teoricamente) que não se tem nenhuma característica lúdica que possa impingir-lhe a demonstrar uma conexão que consista em relação e interação no ato do entretenimento sensorial (sensível), uma vez que, a condição lúdica para se manifestar exige da criança uma significação do comportamento, instituindo-se comunicação com a linguagem.

A forma de pensar tal conexão com a linguagem pode fornecer pistas para a significação do comportamento da criança de modo significativo. É preciso, portanto, possibilitar o encontro dela com o entretenimento adequado, isto é, com aquele que não se satisfaz no simples prazer fisiológico do ato sensorial ao ver desenho animado no écran. Todavia, que possa permitir um avanço na condução da experiência que se estabelece: não é o agradável que leva ao belo, mas é por meio do belo que se deve alcançar o agradável (SCHILLER, 1991).

Enfatiza-se, então, que é por meio do caráter lúdico da produção gráfica da criança que se dará o confronto entre o entretenimento físico e 
o entretenimento livre. O legado significante dessa natureza é motivado pelo desenho animado, que a criança assiste na televisão, e que este pode ser usado como brinquedo. Ressalta-se que a satisfação de necessidades imediatas criadas pela modernidade é um fator preponderante pelo qual ela procura o prazer ao desenha personagens de heróis, fazendoos participativo em sua vida e imitando-os no comportamento lúdico. Diga-se de passagem, desenhar para a criança é expressar-se livremente e deveria ser a busca do prazer estético, cuja espontaneidade se daria pela expressão gráfica, associada à ideia de brincar com a plasticidade envolvente de linhas, texturas, cores etc. Além do mais, o desenho exerce forte influência no comportamento da criança, permitindo revelar-se como uma das modalidades do brincar.

A tradução do efeito processual da ludicidade existente na atividade gráfica da criança envolve um brincar livre e espontâneo com o desenho que realiza, isso inclui prazer estético e comunicabilidade. É preciso saber despertar o interesse no aprendizado espontâneo da criança, pois esse processo de desenhar, por meio do exercício da observação livre no écran da TV, é um modo de qualificar a atenção, a experimentação, a liberdade, o uso da memória, da construção de conhecimento e tantas outras coisas mais. A criança mergulha na imaginação de seus heróis, apropriando-se deles e não deve ocorrer de forma contrária (MALUF, 2003). Acima de tudo, o que está em questão não é porque a criança desenha seus heróis que vê na televisão e sim, em que consiste essa manifestação de ludicidade livre.

A criança ao apropriar-se de um personagem de herói está, verdadeiramente, explorando as possibilidades de brincar com ele. Isso não pode ser dado por um entretenimento meramente físico, pois a imaginação criadora ou plástica não se manifesta nesse ato. Justifica-se a ausência da imaginação plástica pelo simples fato de que o entretenimento físico promove a imediaticidades das sensações e a imaginação precisa de elementos analógicos para ser algo no pensamento da criança (KANT, 1935). Em todo caso, deve-se prestar atenção ao desenho espontâneo na infância, pois este caracteriza o desenvolvimento da criança, já que desenha desde muito cedo - a rabiscação, conforme Brittian e Lowenfel (1980), inicia-se com um ano e seis meses-. Todavia, a constância dessa ação gráfica dependerá das oportunidades que terá, no contato com 
materiais e estímulos adequados dados pelos adultos. O écran pode ser um artefato importante e estimulante que desperta na criança certos aspectos da sensorialidade visual e se estruturará nos esboços das figuras, a partir da constituição da linguagem não-verbal como o audiovisual.

Sem dúvida que o desenho animado no cotidiano doméstico medeia a imaginação reprodutiva e associativa - conforme Kant (1935) -, já que proporciona a imitação das personagens de heróis, quer seja por meio do faz-de-conta ou da representação gráfica. Importa destacar que o écran participa da ampliação perceptual (fisiológica) da criança, mas não possibilita o exercício da imaginação produtiva (criadora ou plástica), devido a percepção ser um aspecto do condicionamento do indivíduo, cuja formação de novos hábitos perceptivos é histórica. Adverte-se que a imaginação produtiva só se desenvolve quando as possibilidades ambientais estão propícias a sua conformação - representação pictórica do espaço, percepção associativa no tempo e invenção artística (CAYGILL, 2000). Para isso, é preciso que exista a possibilidade de a receptividade ser afetada por objetos, conforme instrui Kant (2005), e que altere o estado interno do aparelho cognitivo. De modo que se produza, internamente, ideias a partir das coisas externas ou que se realize operações espontâneas, mas esta última não pode ser resultante de estímulos, simplesmente, operada por um entreter-se em sensações.

\section{O papel comercial das personagens heroicas que habitam a televisão}

Destaca-se como a televisão influi de algum modo na imaginação da criança. O desenho animado é o ponto de referência desse aspecto, apresenta-se à receptividade da criança, constituindo de modo icônico no repertório imaginário e visual das gerações. Historicamente, a televisão, por meio de desenho animado, tem participado da efetiva estimulação da produção gráfica das crianças brasileiras: na década de 1970, os espectadores mirins desenhavam personagens como Super Mouse (Paul Terry, 1942), Pica-pau (Walter Lantz, 1940), Batfino e Karatê (Hall Seeger, 1967), a Pantera Cor de Rosa (Friz Freleng e David DePatie, 1964) etc; na década de 1980, estão as personagens de super-heróis, como He-Man (Filmation Studios, 1983), ThunderCats (Tobin Wolf, 1983), Homem Aranha (Stan 
Lee e Steve Ditko, 1962), Super Man (Joe Shuster e Jerry Siegel, 1938) etc; nos anos de 1990, as figuras inocentes das crianças heroínas e dos "bichinhos" exemplificam-se com As Meninas Super-Poderosas (Craic McCrackem, 1994), o anime Digimon (Akiyoshi Hongo, 1997), Bob Sponja (Stephen Hillenburg, 1999) etc.; na primeira década do século XXI, aparece o anime Hamtaro (Ossamu Nabeshima, 2000), KND (Tom Warberton, 2001), o murikarinime Bem 10 (Ducan Rouleau, Joe Casey, Joe Kelly, Steve T. Seagle, 2005) e outros.

Um grande número de personagens heroicos passaram a habitar o écran. Consequentemente, foram transportados para a forma-brinquedo pela indústria, convivendo culturalmente com a criançada na mídia televisual e nas estantes dos seus quartos. Assim, a cada geração de consumidores, exibe-se uma forma de pensar a sociedade para as gerações seguintes, é a maneira de configurar economicamente a criança na sociedade de produção e consumo, cuja função é adequá-la ao padrão de poder de compra. Mas no encalce da reprodução dos valores ideológicos da sociedade está a substância do "encantamento" e a consolidação paramétrica do público infantil sob a égide de inculcação do paradigma de herói. Rezende e Rezende (1993) fazem um conveniente comentário:

O super-herói é super, ou seja, é um fetiche típico, é ahistórico, temporal, cristalizado em onipotência, isolado numa dimensão de eternidade. Seus efeitos são morais, obedecem aos cânones de uma moral burguesa. O superherói é o outro lado do espelho em que se mirava a bruxa de Branca de Neve; ele corporifica nossos desejos (p. 38).

Notadamente, a manifestação da ludicidade livre na infância se reveste na expressão formal do grafismo que a criança pratica, ou seja, essa prática é substantiva para que o infante se dê conta ou se encontre com a sua realidade. É impossível separar o encanto que circunscreve o super-herói dos desenhos animados, cristalizados em uma forma moral, que vem se constituindo modelo de racionalidade, desde a expropriação do caráter emancipatório da razão pela ideologia vigente. Nesse sentido, ressalta-se que o papel do entretenimento no brincar da criança com os personagens, oriundo deste modelo, está subordinado ao aparato tecnológico, ideológico, pedagógico e social que se configuram na 
manifestação da ludicidade sob o efeito da interação com os elementos sensíveis disponibilizados.

Caso o "herói" consista em traduzir o pensamento ideacional da sociedade, em que o ideal é uma propriedade da causa do consumidor, dirse-á que o "herói pronto" atende os interesses de uma conjuntura social que exige ser consumido e para tal tem que existir o "ser consumidor". Então, a responsabilidade em oferecer entretenimento à criança já preconiza em estabelecer um acervo de imagens visuais, alimentadas pelos desenhos animados, exibidas na televisão. Evidentemente, quem tirará partido desse produto especializado - a imagem do herói -, o qual será alvo de exploração comercial através de uma multiplicidade de novos produtos que derivam dos desenhos animados: mochilas, bonecos, adesivos, calçados, vestuários, alimentos etc. Tudo para manter a criança "conectada".

\section{O efeito processual no desenho do herói - será que vira brinquedo?}

Uma "ecologia" de "produtos prontos" está à disposição dos sentidos sensoriais da criança. Essa diversidade de atraentes de artefatos e imagens não tem outro significado a não ser o consumo. A criança, diante desta circunstância, aceita todas as sensações provenientes de tais produtos indiscriminadamente. No entanto, não se pode afirmar que todo artefato que chega às mãos dela possa se tornar brinquedo. De fato, existem muitos produtos que não os são. Mas há a possibilidade de a criança transformar as coisas em brinquedos. Como fazê-los, então?

Quando a criança brinca espontaneamente, parece ter abandonado o mundo real para embarcar no carrossel da fantasia, longe de qualquer situação criada por adultos. Tudo o que ela toca adquire vida e embarca no carrossel. também Lopes (1998) percebeu que o mundo dos brinquedos se compõe de duas pátrias: aqueles que são fabricados pelos adultos e seguem a concepção lógica são reconhecidos pelo processo de produção técnica artesanal, industrial ou racionalizada; mas há também aqueles que são determinados pelo conteúdo, atribuído pela criança, "[...] pelo uso que faz do brinquedo e dos objetos que se tornam deste modo lúdicos" (LOPES, 1998, p. 218). Pode-se, então, perceber que há brinquedos 
fabricados pelos adultos e outros pelas crianças. Aliás, no carrossel da fantasia participam somente aqueles objetos lúdicos que atende à imaginação da criança.

Nessa perspectiva, o aspecto subjetivo que se comunica com a criança está centralizado na forma como ela usa a imaginação criadora para animar objetos e incluí-lo no brincar. Nesse sentido, a utilidade que a criança dá ao brinquedo, na brincadeira, é o seu conteúdo, já que não podem existir brinquedos, na concepção dela, sem a sua brincadeira. Todavia, pode existir brinquedo sem criança e também sem brincadeiras. Sem mais delongas, dir-se-á que o mais importante, nesse momento, é saber que o desenho gráfico da criança é um artefato lúdico e será brinquedo à medida que faz parte do carrossel da brincadeira.

Sendo assim, o desenho do herói que a criança esboça no papel vai pouco a pouco se construindo num artefato visual, cuja qualidade é lúdica. Revelar-se-á como a conquista de um desafio e aprendizado, mas também uma forma de se comunicar. A elaboração do desenho do herói requisita etapas. Primeiramente a criança explora diversas tentativas, propondo-se imitar a imagem, aguçando o seu poder de observação no écran. Isso exige bastante da percepção, já que também caracteriza um processo de observação direta do objeto imagético e memorização visual, buscando uma representação satisfatória que seja clara e detalhista da figura do modelo, de modo que, tal conexão estabeleça-se em um vínculo entre a imagem televisual e a representação feita pela criança no papel. $O$ infante quer tornar a imagem idêntica a que vê no écran. Por outro lado, a representação gráfica constitui-se na manifestação da ludicidade livre por meio da rabiscação, inclui interatividade sensório-motora e visual, isso requer sucessivas tentativas entre os erros e os acertos.

Esse mecanismo é o princípio que move a manifestação do efeito processual do brincar, cuja exigência dá-se pela conjugação psicovisual da tarefa e envolve a elaboração do grafismo, como um importante exercício de conquistas gráficas, que a criança expressa impulsionada por gestos motores mais amplos (PILLAR, 1996). O processo de desenhar considerando as etapas de tentativas e descobertas - e o próprio desenho, após ser concretizado na superfície do papel, é o território determinado pela manifestação da ludicidade dado pelo brinquedo, neste caso, o que designa-se como brinquedo gráfico. Justifica-se essa denominação pelo 
fato de ser este constituído de imaginação e que permite entretenimento livre da criança. Estabelece-se, então, a relação da imagem como artefato lúdico, o qual tem visualidade e plasticidade capaz de promover, ao comportamento lúdico, estímulo liminoid. Desse modo, a criança pode ressignificar o paradigma do herói que tanto lhe chama atenção e, se assim ocorrer, acabará por reformular a sua versão de mundo.

Ao desenhar seu herói, em casa, ao longo do dia, estabelece uma comunicação silenciosa com a personagem, muitas das vezes dialogando com ela, imaginando diversas situações para seu herói e papéis que se adéque a ele, exigindo-se da imaginação associativa elementos que possam compor seu modo de compreensão (KANT, 1935). É o momento de embarcá-lo no carrossel e conduzi-lo como artefato lúdico na fantasia. A situação imaginária, posta a cada personagem que desenha, instalase por meio da execução gráfica, uma espécie de jogo de faz-de-conta. Assim, é o brinquedo gráfico. Vai além da sensorialidade, do agradável, do entretenimento físico, contém desdobramentos de cunho artístico, estético, lúdico e comunicacional, não deixando de ser entretenimento, porém livre. Em sua importância alcança e promove a comunicação nãoverbal, incentiva o uso da imaginação, habilidades perceptivas, motora e intelectual, indexando novos conceitos, informações, ajudando no desenvolvimento emocional e social.

A criança que desenha para brincar aprende a viver não somente entretida com a imagem televisual, mas dialoga com os desenhos ao realizá-los no papel, exercita a sua qualidade humana. Por isso, esses desenhos feitos por ela também podem ser chamados de desenhosbrinquedos, pois permite experimentar um mundo objetivo de forma subjetiva e que o reelabora, novamente, de forma objetiva por meio de seus desenhos ilustradores. É um ato dominante e necessário, enquanto atividade espontânea e exploratória que servirá para a organização do pensamento, da imaginação e criatividade.

Brincar com a representação gráfico-visual na superfície do papel, com lápis, tinta guache ou canetinha hidrográfica, representa um exercício de aplicabilidade da experiência estética e artística, já que o brincar mobiliza-se por si só no estético e torna-se conectado na brincadeira. Em contra partida, Dewey (1972) ensina que a experiência do sujeito não está dissociada dos atributos estéticos, posto que seja por meio do estético 
que se impregna a vida do homem como ser sensível e consciente de sua atuação no mundo cultural. Aliás, a experiência estética é condição da receptividade do sujeito com os objetos. É uma forma de está lúcido no mundo.

Se alguém é capaz de sensibilizar-se pelas sensações emanadas dos objetos e em si mesmo produzir um entendimento do mundo de forma significativa, é porque ela está traduzindo, em forma simbólica, aquilo que, diante do seu olhar, possa ser consolidado como algo significante em sua vida. Então, teve despertado em si mesmo o interesse pelo mundo ao alcance do seu olhar. A partir dessa compreensão, se o desenho que a criança faz é resultante da experiência de assistir à televisão, entender-seá, com isso, que poderá ser importante, porque estaria a articular o meio para se compor à experiência estética como experiência intelectual, num desafio surpreendente que mobiliza o entendimento verbal e não-verbal da comunicação visual e lúdica.

Interpretar, então, seria somente uma forma de a criança imaginar possibilidades de transformação das coisas que alimentam o seu repertório imagético. Em vista de que, transformar um objeto visual em um esboço gráfico e tomá-lo como desenho-brinquedo é uma forma estética significativa de usar a comunicação lúdica. Uma comunicação visual da imagem viva de uma personagem que dialoga constantemente com a criança.

Se, entretanto, esta imagem invadir a criança de forma inapropriada, habitar apenas o olhar físico, promovendo experimentações em suas ações nervosas, dominar todo o seu ser, é um reflexo de que algo não vai bem com a criança. Já que a extensão da televisão não deve comprometer a individualidade do infante, o corpo deste não deve ser a expansão do écran eletrônico e nem deverá atingi-lo pela instrumentabilidade do idêntico, impregnado por um falso saber, no gesto, na ação, no olhar, na fala, na forma de se vestir, gosto etc. O seu carrossel está ancorado no porto da razão instrumental e sente dificuldade de partir. Ao se observar um infante afetado cenicamente apenas pelo reconhecimento do herói, emprestando ao personagem seu corpo, pode-se desconfiar da experiência que ele está a vivenciar. De fato, não se deve confundir o jogo de faz-deconta com a simples reprodução. Brincar com o desenho de heróis no papel é comunicação e expressão, mas envolve um aprendizado solitário diante do écran.

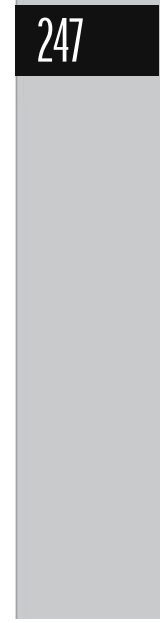




\section{Elementos finais da reflexão}

Pode-se repensar sobre a evolução dos momentos da criança e de suas conquistas com a experiência criativa, como sendo o momento pelo qual a criança atribui-se a uma significação lúdica, porque constrói um conteúdo para o seu artefato lúdico, embarcando-o no carrossel da brincadeira. Três etapas podem ser elencadas como conquista do seu próprio desafio: a primeira consiste em execução e elaboração do desenho apreendido, por meio do exercício de observação diante do écran, caracterizada por muitas tentativas e fracassos: a criança experimenta riscar, de um jeito e de outro, até que, depois de dias de tentativas, a representação começa a tomar forma semelhante ao modelo visual; a criança desenha aquilo que vê e não o que pensa saber (ARNHEIM, 1980); o segundo momento trata da experiência tomada pela forma, organiza-se o pensamento criador e passa a controlar melhor o material gráfico, preocupando-se com a ocupação do espaço no papel; a terceira consiste no domínio da expressão gráfica, uso da memória visual, a representação visual ganha um corpo inteligível, o desenho é realizado sem dificuldade, representá-lo é só uma oportunidade de mostrá-lo a alguém que se interesse por ele.

Há de se considerar o efeito processual do brincar, pois este se manifesta desde que a criança se entrete com o fazer de forma livre. Isso significa que o brincar com o desenho passa a ser uma tarefa que a criança cultiva participativamente com outras crianças. Socializa seu aprendizado individual, influindo na percepção pessoal e dos colegas que passam a admirá-la, promovendo auto-estima e integração social. É um aprendizado que não está no nível dos bancos escolares e nem tem importância para a escola, porque é uma atividade liminoid, pois, muitas vezes, é invisível aos olhares dos professores que ignoram essa prática do fazer como comunicação, expressão e ludicidade.

A imagem televisual deveria ser encarada como um importante veículo de estimulação social, pois transita quotidianamente entre o espaço privado-doméstico e o público escolar. Tem toda a simpatia das crianças estas se estabelecem em comunicação silenciosa e se abrem à interação sensorial individualizada com aquela. Porém, se a escola se interessasse e desse a oportunidade de os alunos brincarem com a imagem televisual, quer fosse na "apreciação", no desenhar ou na busca de desvendar o 
segredo da linguagem da animação, certamente, a sua manipulação, no âmbito da comunicação lúdica, teria outro resultado. Mas não através da instrumentalização do brincar, pois isso fere a ética e a liberdade humana e, consequentemente, desvaloriza o caráter livre do ser estético e criador, engessando a ideia de consequencialidade firmada pela ludicidade.

O que falta é perceber que a ludicidade faz parte de toda a vida do homem e não somente é um aspecto da infância. Os adultos esquecem que também participam de uma diversidade de comportamentos que se nomeiam como brincar, jogar, recrear, lazer e construir artefatos lúdicos e de criatividade. Por isso, devem considerar o écran da TV como uma ferramenta audiovisual que amplia as possibilidades das crianças, desde que esta estejam no processo de relação e interação com a ludicidade, protagonizando ao comportamento significação lúdica.

\section{REFERÊNCIAS}

ARENDT, H. A Condição Humana. Trad. Roberto Raposo. 10 $10^{\mathrm{a}} \mathrm{Ed}$. Rio de Janeiro: Forense Universitária, 2007.

ARNHEIM, R. Arte e Percepção Visual: uma psicologia da visão criadora. Trad. Ivone Terezinha de Faria. São Paulo: Pioneira/USP, 1980.

BENJAMIN, W. Velhos brinquedos: sobre a exposição de brinquedos no Märkische Museum. In: BENJAMIN, W. Reflexões sobre a criança, o brinquedo e a educação. Trad. Macus Vinicius Mazzari. São Paulo: Ed. 34, 2002.

CAYGILL, H. Dicionário Kant. Trad. Álvaro Cabral. Rio de Janeiro: Jorge Zahar, 2000.

DEWEY, J. El Arte como Experiencia. Versión española: Samuel Ramos. México/Buenos Aires: Fundo de Cultura Económica, 1972.

FUSARI, M. F. R. O Educador e o Desenho Animado que a Criança Vê na Televisão. São Paulo: Loyola, 1985.

LOPES, M. C. O. Comunicação e Ludicidade na Formação do Cidadão Pré-escolar. Tese de Doutorado. Aveiro: Universidade de Aveiro, 1998.

Ludicidade explicação do conceito. $1^{\circ}$ Congresso Internacional em Estudos da Criança: Infâncias possíveis, mundos reais. 
Braga (PT): Instituto de Estudos da Criança/Universidade do Minho, 2008.

LOWENFELD, V.; BRITTAIN, W. L. Desenvolvimento da Capacidade Criadora. Trad. Álvaro Cabral. São Paulo: Mestre Jou, 1970.

LUQUET, G. H. O Desenho Infantil. Trad. de Maria Teresa Gonçalves de Azevedo. Porto: Barcelos, 1969.

KANT, I. Crítica da faculdade do juízo. Trad. Valério Rohden e António Marques. 2 ${ }^{\mathrm{a}}$. Ed. Rio de Janeiro: Forense Universitária, 2005.

Antropologia: em sentido pragmático. Trad. de José Gaos. Madrid: Revista do Occidente, 1935.

MALUF, A. C. M. Brincar: prazer e aprendizado. Petrópolis: Vozes, 2003.

PILlAR, A. D. Desenho e Construção de Conhecimento na Criança. Porto Alegre: Artes Médicas, 1996.

REZENDE, A. L. M.; REZENDE, N. B. A TV e a Criança que te Vê. $2^{a}$. ed. São Paulo: Cortez, 1993.

SCHILLER, F. Teoria da Tragédia. Trad. Anatol Rosenfeld. São Paulo: EPU, 1991.

WILSON, B.; WILSON, M. Os Super-Heróis de J.C. Holtz: mais um esboço de uma teoria da arte Infantil. Trad. Maria Lúcia Batezar Duarte e Maria Nilza Macedo de Assunção. E. U. A: Arte Educação,1974. 